\title{
Application of laser ultrasonics to monitor microstructure evolution in Inconel 718 superalloy
}

\author{
Thomas Garcin ${ }^{1}$, Jean-Hubert Schmitt ${ }^{2}$, a , and Matthias Militzer ${ }^{1}$ \\ ${ }^{1}$ The Centre for Metallurgical Process Engineering, The University of British Columbia, 309-6350 Stores Rd., \\ Vancouver, BC, Canada V6T 1Z4 \\ 2 Ecole Centrale Paris, Laboratoire MSSMat - UMR CNRS 8579, Grande voie des Vignes, 92295 Châtenay Malabry, \\ France
}

\begin{abstract}
Laser ultrasonics for metallurgy is an innovative sensor dedicated to the measurement of microstructure evolution during thermomechanical processing. In this technique, broadband ultrasound pulses are generated and detected with lasers. The properties of the ultrasounds are then related to the characteristics of the microstructure. Ultrasound attenuation is primary originated by the scattering at grain boundaries and its frequency dependence can be related to the grain size. The present work aims to introduce this technology as an exciting tool for metallurgists. As an illustration of its capability, the evolution of the grain size during isothermal annealing from a fine grained structure is in-situ monitored in an Inconel 718 superalloy. Laser ultrasonic measurements are compared with ex-situ metallography observations. Indication of heterogeneous grain growth is observed, correlated to the dissolution of $\delta$-phase particles present in the initial structure. This preliminary study illustrates the potential of this new technique to monitor microstructure evolution in more complex scenarios including recrystallization during simulation of hot forging processes.
\end{abstract}

\section{Introduction}

Non-destructive techniques can be used to quantify the microstructure in materials and its evolution during thermomechanical treatment. For example, ultrasonic testing is known to detect defects and cracks in the structures, but can also be utilized to evaluate some material parameters such as texture or grain size [1]. Ultrasonic evaluation of microstructure is based on the correlation between the ultrasound wave properties and microstructure parameters. Conventional contact ultrasonic techniques are, however, not a practical tool to monitor microstructure evolution during thermomechanical processing. To mitigate this drawback, a revolutionary technology was developed in the past two decades to generate and detect ultrasonic waves using pulsed lasers [2]. Measurements of microstructure evolution can now be conducted remotely and in realtime on a sample during thermomechanical treatments. Grain growth, phase transformation and recrystallization processes were successfully monitored by the laser ultrasonic technique in a wide range of materials such as steel, aluminium and zirconium alloys [3-12].

The mechanical properties of forged Inconel 718 parts are directly linked to the final grain size [13-15] which is mainly controlled by dynamic recrystallization occurring during hot forging, and depends on the initial grain size [16-18]. Further, the forging temperature is a critical

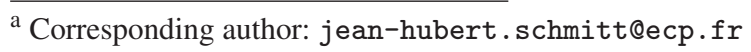

parameter as the $\delta$-phase dissolves above $980{ }^{\circ} \mathrm{C}$ leading to substantial grain growth prior to deformation [19-22].

This paper aims to present the use of a laser ultrasonic system to monitor in real time grain growth during annealing in the super- $\delta$-solvus temperature range prior to the forging of Inconel 718 samples. The present research validates the use of laser ultrasonics for grain size measurements in nickel-based superalloys. Further applications of the technique will be evaluated to monitor microstructure evolution during the heating and deformation processes.

\section{Material and experiments}

The material used in this study is an Inconel 718 superalloy whose typical chemical composition in weight percent is indicated in Table 1. Post casting heat treatments were performed to get a well recrystallized homogeneous grain structure with a grain size of approximately $20 \mu \mathrm{m}$ (Fig. 1a). The $\delta$-phase precipitates are mainly located along the grain boundaries and their volume fraction was previously determined to be about 3\% [23]. In the present study cylindrical samples were used with a diameter of $10 \mathrm{~mm}$ and a length of $15 \mathrm{~mm}$. The selection of this sample geometry was based on the long term view to also monitor recrystallization in hot compression tests. Experiments were conducted in a Gleeble 3500 thermomechanical simulator (Dynamic Systems Inc.). The test chamber is backfilled with high purity argon gas after evacuating up to a vacuum of $0.5 \mathrm{~Pa}$. The temperature is controlled with

This is an Open Access article distributed under the terms of the Creative Commons Attribution License 4.0, which permits unrestricted use, distribution, and reproduction in any medium, provided the original work is properly cited. 
Table 1. Nominal chemical composition range (in weight percent) of Inconel 718.

\begin{tabular}{|l|c|c|}
\hline Element & Min & Max \\
\hline $\mathrm{Ni}$ & 50 & 55 \\
\hline $\mathrm{Fe}$ & bal & bal \\
\hline $\mathrm{Cr}$ & 17 & 21 \\
\hline $\mathrm{Mo}$ & 2.8 & 3.3 \\
\hline $\mathrm{Nb}+\mathrm{Ta}$ & 4.8 & 5.5 \\
\hline $\mathrm{Ti}$ & 0.7 & 1.2 \\
\hline $\mathrm{Al}$ & 0.4 & 0.8 \\
\hline $\mathrm{Co}$ & 0 & 1 \\
\hline
\end{tabular}

thermocouples spot-welded at the centre of the sample. The temperature homogeneity was verified to be within $10^{\circ} \mathrm{C}$ between the centre and the edges across the length of the sample. The samples are heated at $10^{\circ} \mathrm{C} / \mathrm{s}$ up to $1000^{\circ} \mathrm{C}$, then at $5^{\circ} \mathrm{C} / \mathrm{s}$ to $1050{ }^{\circ} \mathrm{C}$, to limit any overshoot. The samples were held at $1050{ }^{\circ} \mathrm{C}$ for various times ranging from 30 to 900 s. At the end of the soaking time, samples were quenched with helium gas to room temperature (A cooling rate of about $100{ }^{\circ} \mathrm{C} / \mathrm{s}$ was obtained in the range from 1050 to $500^{\circ} \mathrm{C}$ ).

Optical metallography is performed on sections cut perpendicularly to the long axis of the cylinder, at the centre length of the sample. For grain observation, the surface is polished and chemically etched with a Kalling solution.

During each test the grain size evolution was measured in-situ using the Laser Ultrasonics for Metallurgy (LUMet) sensor that is attached to the rear of the Gleeble chamber. Ultrasound waves are generated by a frequency-doubled Q-switched Nd:YAG laser with a wavelength of $532 \mathrm{~nm}$ and beam spot size of $1.5 \mathrm{~mm}$. The pulse duration is about $6 \mathrm{~ns}$ and delivers a maximum energy of $72 \mathrm{~mJ}$. The laser produces a wide band compressive ultrasound pulse by vaporizing a small volume of material at the surface (a few nm per pulse). The waves are detected at the sample surface with a frequency-stabilized $\mathrm{Nd}$ :YAG pulsed laser which illuminates the surface with an infrared radiation $(1064 \mu \mathrm{m})$ during $90 \mu \mathrm{s}$. The light reflected by the surface is then demodulated using an active interferometer approach [24].

\section{Results}

\subsection{Metallographic measurements}

Figure 1 shows the metallographic observations of grain growth resulting from the holding at $1050{ }^{\circ} \mathrm{C}$. After holding for 900 s the average grain size has increased by about a factor 4 as can be inferred from the difference in the micrograph magnifications (Fig. 1a vs. Fig. 1c). Further, a significant amount of annealing twins is observed. Moreover, observation of the microstructure at higher magnification shows that the $\delta$-phase is almost completely dissolved after $900 \mathrm{~s}$. The final size of the grains, excluding the twins, is fairly homogeneous.

For intermediate soaking times, i.e. between 30 and $230 \mathrm{~s}$, the situation is more complex. The $\delta$-phase precipitates are still present, however distributed heterogeneously in the microstructure, presumably due to $\mathrm{Nb}$
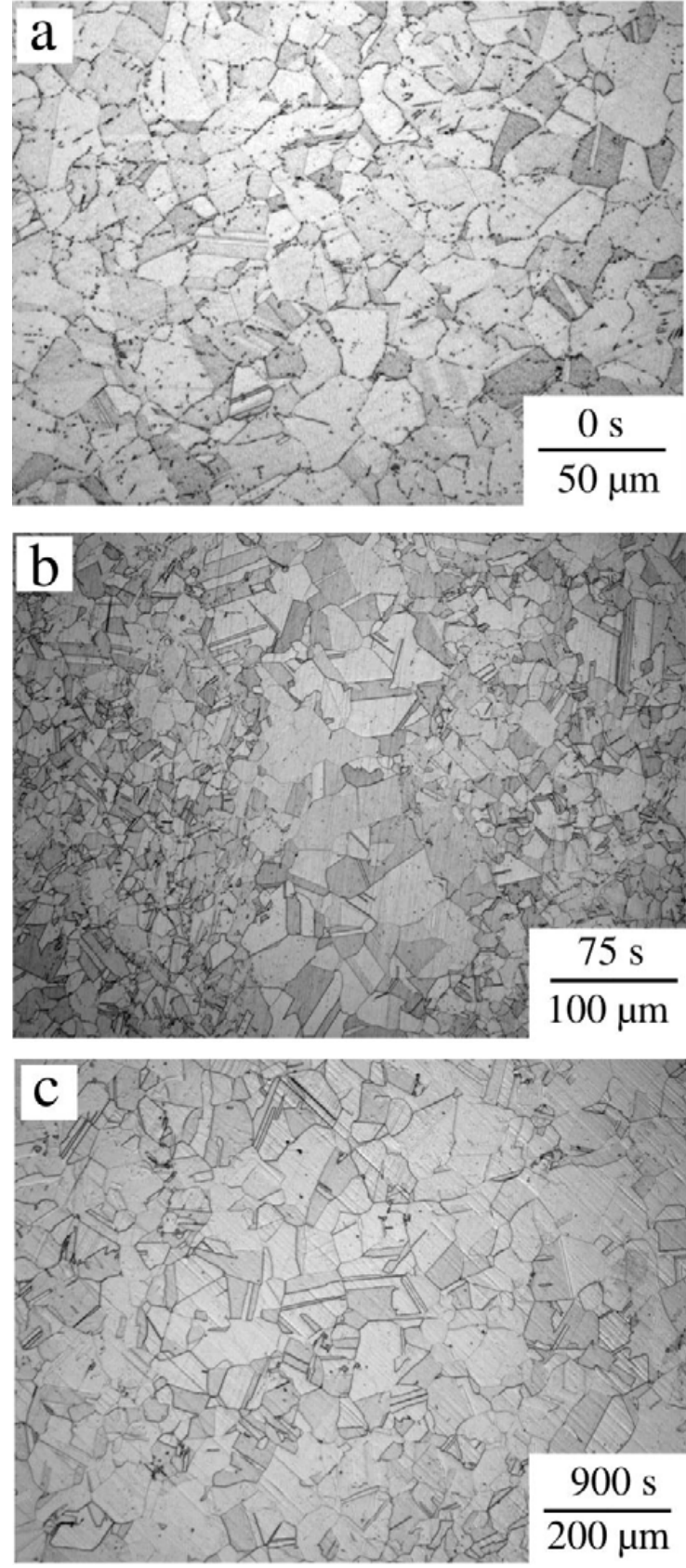

Figure 1. Optical micrograph of the sample after a) $0 \mathrm{~s}$, b) $75 \mathrm{~s}$, c) $900 \mathrm{~s}$, at $1050^{\circ} \mathrm{C}$.

segregation. Accordingly, grain growth occurs heterogeneously (see for example Fig. $1 \mathrm{~b}$ after $75 \mathrm{~s}$ ).

These observations are consistent with previous investigations on the stability of the $\delta$-phase precipitates. It was shown that their dissolution is relatively slow. For example, a decrease by a third of the initial volume fraction was reported after $100 \mathrm{~s}$ at $1020^{\circ} \mathrm{C}$ [25-27]. Further, grain growth is very sensitive to the $\delta$-phase volume fraction. Limited grain growth was observed above $2 \%$ whereas substantial growth was reported when the volume fraction decreases below $1.5 \%$ [27].

To further quantify grain growth in the present case, the average grain size is quantified using the mean equivalent area diameter (EQAD), calculated with $\sqrt{\pi \bar{A} / 4}$ where 
Table 2. Average and maximum grain sizes (in $\mu \mathrm{m}$ ) during annealing at $1050^{\circ} \mathrm{C}$.

\begin{tabular}{|l|c|c|c|}
\hline Time & $E Q A D$ & $D_{\text {MAX }}$ & $D_{\text {MAX }} / E Q A D$ \\
\hline 0 & 24 & 53 & 2.2 \\
\hline 30 & 27 & 65 & 2.4 \\
\hline 75 & 33 & 94 & 2.9 \\
\hline 130 & 37 & 115 & 3.1 \\
\hline 175 & 44 & 128 & 2.9 \\
\hline 230 & 46 & 130 & 2.8 \\
\hline 480 & 62 & 166 & 2.7 \\
\hline 900 & 82 & 199 & 2.4 \\
\hline
\end{tabular}

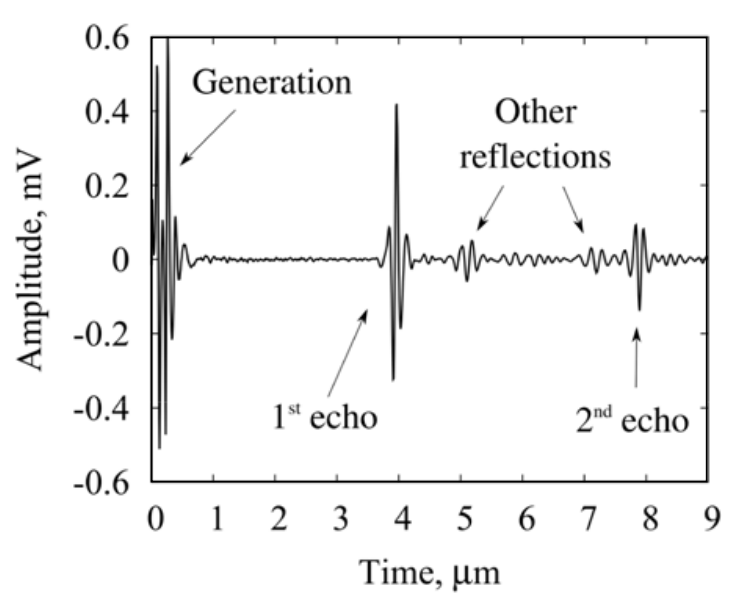

Figure 2. Ultrasound waveform measured at the beginning of the soaking time at $1050^{\circ} \mathrm{C}$.

$\bar{A}$ is the arithmetic average of the grain areas. At least 400 grains are measured for each microstructure in order to provide sufficient statistics. In addition, a maximum grain size value $D_{M A X}$ is defined by averaging the equivalent area diameters of the $1 \%$ largest grains. The ratio $D_{M A X} / E Q A D$, constitutes a measure of the width of the grain size distribution. The maximum grain size approach is in particular relevant in the context of laser ultrasonic measurements as attenuation is dominated by the largest grains in the distribution.

The different grain size parameters are summarized in Table 2. They confirm the increase of grain size with time and the temporary increase of the width of the grain size ranges. The ratio $D_{M A X} / E Q A D$ shows a maximum at $130 \mathrm{~s}$ due to the heterogeneous nature of grain growth (see Fig. 1b).

\subsection{Laser ultrasonic results}

A typical ultrasound waveform is shown in Fig. 2. The initial oscillations at $0 \mu \mathrm{s}$ correspond to the noise created by the generation process. At about $4 \mu \mathrm{s}$ the first echo arrives at the generation surface, which corresponds to the initial pressure pulse having travelled twice through the sample in the direction perpendicular to the generation surface. After doubling that time, the pulse has traversed through the sample once again such that a second echo is measured. The other peaks observed between these two echoes correspond to waves travelling in other direction and/or having other modes of propagation.
The maximum amplitude of each echo is centred in a window with a width of $0.45 \mu \mathrm{s}$. The amplitude spectrum is calculated with a Fast Fourier Transform algorithm. A noise filter is applied to keep a signal to noise ratio higher than 10. In the present case, it gives a bandwidth range between 4 and $15 \mathrm{MHz}$ with a $3.3 \mathrm{MHz}$ frequency resolution. The attenuation spectrum is then evaluated by comparing the amplitude spectrum of the first echo measured in each waveform relative to the amplitude spectrum of the first echo measured at the beginning of the soaking, i.e.:

$$
\alpha(f)=-\frac{20}{2 d} \log 10\left(\frac{g(f) A_{t}(f)}{g(f) A_{0}(f)}\right)
$$

where $f$ is the frequency, $d$ is the sample diameter, $g(f)$ is the frequency dependent gain that can be assumed to remain constant during the measurement, and the pulse amplitude is $A_{t}$ for the signal at time, $t$, and $A_{0}$ for the reference signal at time $t=0$.

The attenuation can be fitted by a power law over the frequency such as:

$$
\alpha(f)=a+b f^{n}
$$

where $n$ is an exponent depending on the wave scattering regime; $a$ and $b$ are the scattering parameters. Here, $b$ is a function of the grain size. When the wavelength is much larger than the average grain size (Raleigh scattering), $n$ tends toward 4. In stochastic scattering conditions (the wavelength is of the order of the average grain size), $n$ is close to 2 [29]. For most of the experiments on polycrystalline metals, it is convenient to consider only one regime of scattering. The exponent $n$ can then be approximated by an intermediate value of 3 [7]. This value has been used in the present analysis.

Figure $3 \mathrm{a}$ shows the attenuation spectrum for different holding times. Regressions according to Eq. (2) are presented by dotted lines in Fig. 3a, with the attenuation spectrum measured for different times during the soaking at $1050^{\circ} \mathrm{C}$. The attenuation at the beginning of the test $(t=0 \mathrm{~s})$ is per definition zero as this waveform is taken as the reference. At the other times, the attenuation increases with frequency.

The absolute value of attenuation at $4 \mathrm{MHz}$ also increases with time. The non-frequency dependent term ( $a$ in Eq. (2)) is associated with other sources of attenuation such as internal friction, but also sample surface reflectivity. The evolution of parameter $b$ with time is shown in Fig. 3b. Here, also the $b$-values at the end of the tests with shorter holding times are given by the symbols indicating excellent reproducibility of the laser ultrasonic measurements. As the holding times increase beyond 600 $\mathrm{s}$ a significant increase in the scatter of the data is observed that can be attributed to a gradual surface damage as a result of repeated ablation by the generation laser.

\section{Discussion}

The single reference echo technique to represent the laser ultrasonic measurement was introduced as a more reliable alternative to the conventional two echo technique, as it 

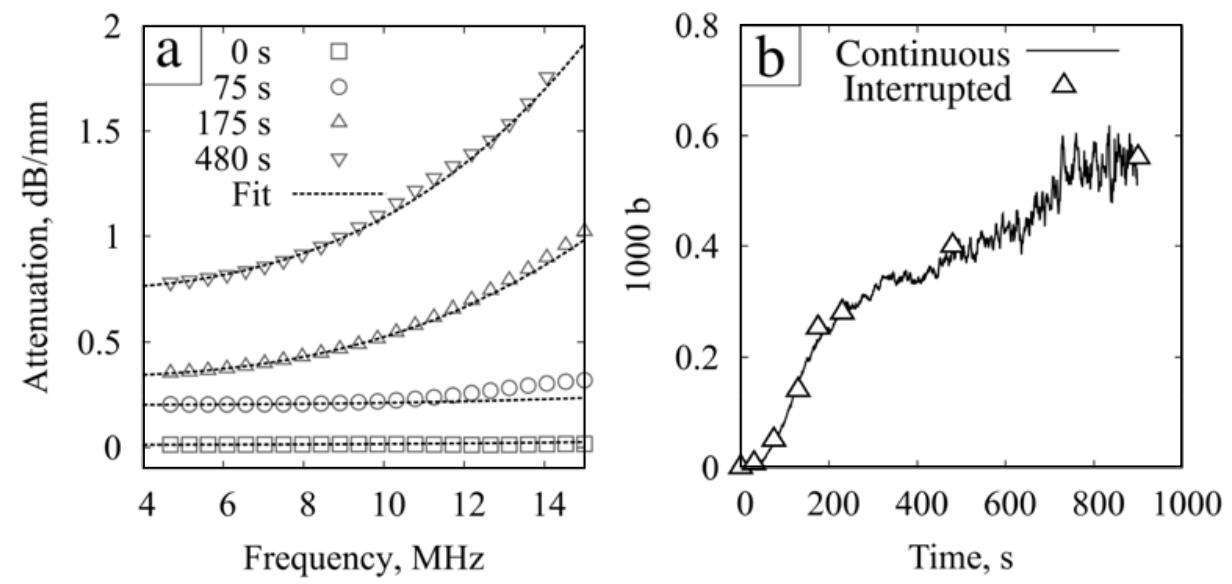

Figure 3. a) Attenuation spectrum measured after $0,75,175$, and $480 \mathrm{~s}$ at $1050^{\circ} \mathrm{C}$. b) Frequency dependent contribution of the attenuation spectrum, $b$, plotted versus time. Open triangles correspond to the value of the parameter $b$ at the end of the soaking time in interrupted experiments for metallographic observations.
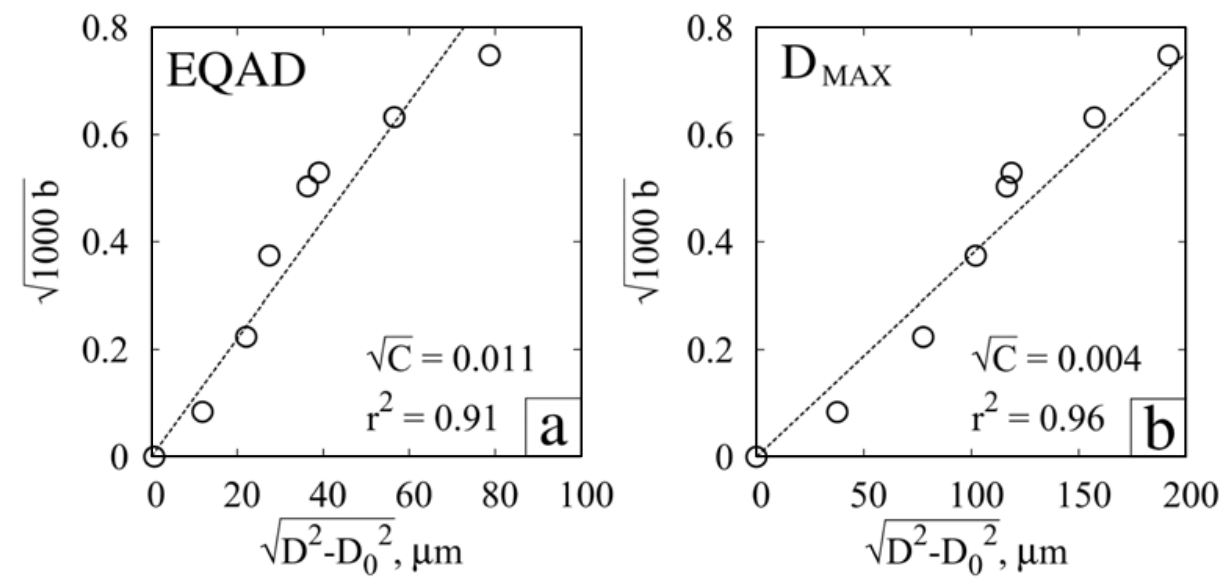

Figure 4. Square root of the ultrasound grain size parameter vs. relative change in grain size expressed in terms of a) EQAD and b) $D_{M A X}$ (see Table 2).

is often challenging to obtain a sufficiently good second echo. Further, the reference echo should preferably be chosen such that grain scattering is negligible for this echo, i.e. the reference sample state must then have a sufficiently small grain size, typically below $5 \mu \mathrm{m}$. According to [28], Eq. (2) can then be expressed to account for the average grain size, $D$ :

$$
\alpha(f)=a+C D^{n-1} f^{n}
$$

where $C$ is a material and temperature dependent parameter. In the present case, it was not possible to create a reference state with a sufficiently small grain size. Nevertheless, considering the initial grain size $D_{0}$ as the reference state of the microstructure, it is possible to express a relative change in attenuation and its grain size dependent parameter b. With $n$ equal to 3, Eq. (2) can be expressed as:

$$
\alpha(f)=a+C\left[D^{2}(t)-D_{0}^{2}\left(t_{0}\right)\right] f^{3} .
$$

It then follows that the parameter $b$ in Eq. (2) is a function of the average grain diameter such that:

$$
b(t, D)=C\left(D^{2}(t)-D_{0}^{2}\left(t_{0}\right)\right) .
$$

Figure 4 presents the parameter $b$ measured at the end of each interrupted treatment with respect to metallographically measured grain sizes. The $C$-value is indicated in Fig. 4 together with the correlation coefficient $r^{2}$ associated with the linear regression.

In a first approximation, the increase of $b$ with time correlates with the increase in grain size. However, the correlation is not fully satisfactory even though an improvement is obtained when taking the maximum grain size instead of the average grain size. The main difference is for the intermediate soaking times at which two grain sizes clearly co-exist. Therefore, a more sophisticated approach needs to be adopted to provide correct interpretation of the state of the microstructure in this time range.

Nevertheless, the current laser ultrasonic measurements provide an excellent insight into the grain growth behaviour. The results shown in Fig. $3 \mathrm{~b}$ clearly reveal the three different grain growth stages observed metallographically (Fig. 1). Initially there is a stage of negligible grain growth with no change in $b$ for the first $30 \mathrm{~s}$ followed by a rapid increase due to heterogeneous grain growth where locally rapid grain coarsening occurs. Subsequently, i.e. after $230 \mathrm{~s}, b$ increases more moderately 

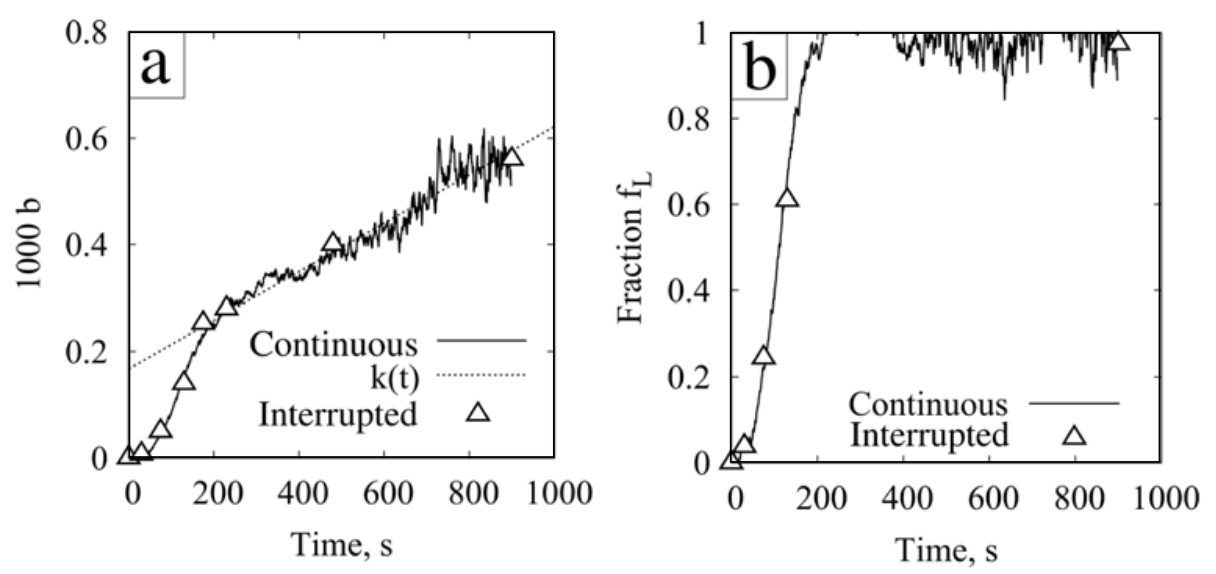

Figure 5. a) Linear regression on the grain size parameter with respect to time based on times larger than $300 \mathrm{~s}$. b) Fraction of grains that have started to grow as a function of time.

almost linearly with time. This variation is in agreement with a scenario of normal grain growth, when a linear relation is observed between the square of the average grain size and time.

At the first stages of soaking, the grains are impeded by the $\delta$-phase precipitates. A certain fraction of the grains remains pinned for a substantial amount of time while others start to grow. In a first approximation, the regions of larger grains can be considered as regions of normal grain growth where the precipitates only weakly influence the growth kinetics. The large grain areas increase due to the gradual dissolution of the $\delta$-phase precipitates and replace the fine grain areas. The associated rapid change in overall grain size is depicted by the fast increase of $b$ between 30 and $230 \mathrm{~s}$. Finally, the variation of the attenuation parameter $b$ for times larger than $230 \mathrm{~s}$ is associated with the normal growth of the larger grains. In this interpretation, the period of heterogeneous growth can be concluded from the laser ultrasonic measurement. For this purpose, the fraction of large grains, $f_{L}$, can be defined as a function of time:

$$
f_{L}=1,000 . b(t) / k(t)
$$

with $k(t)$ being the linear extrapolation of the variation of $b(t)$ after a long soaking time (Fig. 5a). This evaluation indicates that after 200 to $300 \mathrm{~s}$, all the grains have started to grow in the structure (Fig. 5b). It gives a first indication of the time required by the $\delta$-phase precipitates to unpin all the grain boundaries.

This observation illustrate the practical use of such real-time measurements for the evaluation of the exact time when the $\delta$-phase becomes inoperative, while the grain size before hot forging is rather homogeneous and not too large.

\section{Conclusions}

Isothermal heat treatments were performed on INCO 718 samples to follow the grain growth during the dissolution of the $\delta$-phase. At $1,050{ }^{\circ} \mathrm{C}$, it was shown that between 30 and $230 \mathrm{~s}$ the resulting grain structure is heterogeneous within the material. This is linked with the progressive dissolution of the $\delta$-phase and a possible heterogeneity of the precipitate distribution. For larger soaking times, the grain size is rather homogeneous and follows a normal grain growth pattern.

The Laser Ultrasonics for Metallurgy (LUMet) technique has proved to be efficient to record the grain size evolution in the investigated Ni-based superalloy. In particular, it has been possible to record the transition from heterogeneous to normal grain growth, i.e. to record the time during which the $\delta$-phase is efficient to pin at least some grain boundaries. For these studies, cylindrical samples have been used that are suitable for hot compression tests. Thus, these initial results are encouraging to extend laser ultrasonic studies to monitor static and dynamic recrystallization in superalloys.

The authors would like to acknowledge the financial support received from the Natural Sciences and Engineering Research Council (NSERC) of Canada. Aubert \& Duval (France) are thanked for providing the material and test samples.

\section{References}

[1] R. B. Thompson and D. O. Thompson: Proc. IEEE, 1985, vol. 73, pp. 1716-55

[2] J. P. Monchalin: Rev. Quant. Nondestruct. Eval., 2004, vol. 23, pp. 3-31

[3] A Moreau, D Lévesque, M Lord, M Dubois, J $\mathrm{P}$ Monchalin, $\mathrm{C}$ Padioleau, and $\mathrm{J} \mathrm{F}$ Bussière: Ultrasonics, 2002, vol. 40, pp. 1047-56

[4] M. Dubois, M. Militzer, A.Moreau, and J. F. Bussière: Scripta. Mater., 2000, vol. 42, pp. 867-74

[5] S. Kruger, G. Lamouche, J.P. Monchalin, R. Kolark, G. Jeskey, and M. Choquel: Iron Steel Technol., 2005, vol. 2, pp. 25-31

[6] S. Sarkar, A. Moreau, M. Militzer, and W.J. Poole: Metall. Mater. Trans. A, 2008, vol. 39, pp. 897-907

[7] M. Maalekian, R. Radis, M. Militzer, A. Moreau, and W.J. Poole: Acta Mater., 2012, vol. 60, pp. 1015-26

[8] S.E. Kruger and E.B. Damm: Mater. Sci. Eng. A, 2006, vol. 425, pp. 238-43

[9] S.E. Kruger, S. Bolognini, G. Lamouche, and A. Moreau: in Quant. Nondestruct. Eval. AIP Conf. Proceedings, Vol. 615, AIP, 2002, pp. 1518-25 
[10] S.E. Kruger, A. Moreau, M. Militzer, and T. Biggs: Mater. Sci. Forum, 2003, vol. 426, pp. 483-488

[11] A. Moreau, C. Bescond, S. Bolognini, M. Lord, S.E. Kruger, and C.S. Man: Automation \& Control/ Advanced OnLine Metallurgical Models/Sensors, 2005, Materials Science \& Technology, pp. 3-10

[12] A. Moreau, P.J. Kielczynski, J.F. Buissiere, and J.H. Root: in Nondestruct. Charact. Mater. VI, R.E.Green, ed., Plenum Press, New York, 1994, pp. 119-128

[13] R. C. Reed: The Superalloys: Fundamentals and Applications, Cambridge University Press, 2006, p. 372

[14] B. Geddes, H. Leon, and X. Huang: Superalloys: Alloying and Performance, ASM International, 2010, p. 176

[15] R. Cozar and A. Pineau: Metall. Trans., 1973, vol. 4, pp. 47-59

[16] M.S. Lewandowski and R.A. Overfelt: Acta Mater., 1999, vol. 47, pp. 4695-4710

[17] R. A. P. Djaic and J. J. Jonas: Metall. Trans., 1973, vol. 4, pp. 621-24

[18] N.K. Park, I.S. Kim, Y.S. Na, and J.T. Yeom: J. Mater. Process. Technol., 2001, vol. 111, pp. 98-102

[19] N. Spath, V. Zerrouki, P. Poubanne, and J.Y. Guedou: in Superalloys 718, 625, 706 Var. Deriv., E.A. Loria, ed., TMS, 2001, pp. 173-83
[20] D. Zhao and P.K. Chaudhury: in Superalloys 718, 625, 706 Var. Deriv., TMS, Warrendale, PA, 1994, pp. 301-13

[21] H. Yuan and W.C. Liu: Mater. Sci. Eng. A, 2005, vol. 408, pp. 281-89

[22] S.C. Medeiros, Y.V.R.K. Prasad, W.G. Frazier, and R Srinivasan: Mater. Sci. Eng. A, 2000, vol. 293, pp. 198-207

[23] J. De Jaeger, “ Contribution à l'étude mésoscopique de la recristallisation dynamique de l'Inconel 718 lors du forgeage à chaud: Approches expérimentale et numérique ", Ph.D. Dissertation, Ecole Centrale Paris (2013)

[24] R.K. Ing and J.P. Monchalin: Appl. Phys. Lett., 1991, vol. 59, pp. 3233-35

[25] S. Azadian, L.Y. Wei, and R. Warren: Mater. Charact., 2004, vol. 53, pp. 7-16

[26] D. Cai, W. Zhang, P. Nie, W. Liu, and M. Yao: Mater. Charact., 2007, vol. 58, pp. 220-25

[27] A.W. Dix, J.M. Hyzak, and R.P. Singh: in Superalloys 1992, E.A. Loria, ed., TMS, Warrendale, PA, 1992, pp. 23-32

[28] E.P. Papadakis: J. Acoust. Soc. Am., 1965, vol. 37, pp. $703-10$

[29] F.E. Stanke and G.S. Kino: J. Acoust. Soc. Am., 1984, vol. 75, pp. 665-81 